\title{
Transmission of Audio Signal from Reed- Solomon AWGN Channel Using Wavelet Transform Families
}

\author{
S. Karagol, and D. Yildiz
}

\begin{abstract}
Mobile communication has become an important part of our daily lives for voice communication, data sharing and access over the Internet. Mobile communication is an open network, so maintaining the privacy and reliability of data has always been anxiety. The reliability of the data against channel noise can be achieved by various error correction codes. The primary purpose of the channel coding process is to reduce the effect of disturbing influences to the minimum level. In this way, the receiver will be able to receive the data sent by the transmitter with the minimum error. In this research paper, it is required to acquire two audio signals with 8 bits of resolution and $8 \mathrm{kHz}$ sampling frequency for 5 seconds in MATLAB. In the first part of this study, ReedSolomon (RS) Coding Method was used to transmit two audio data recorded in .wav format with minimum error. Binary Phase Shift Keying (BPSK) modulation was used as the modulation method. The Bit Error Rate (BER) performance curve was plotted and the difference between the original and the received signal was observed. According to the BER performance curve, as the signal to noise ratio increases, less false data is received at the receiver. In the second part of the study, four wavelet transform families at different levels were applied to the audio signal, and the performances of these classes were compared.
\end{abstract}

Index Terms - Audio Signal, Channel Coding, Reed-Solomon Coding, Wavelet Transform Families.

\section{INTRODUCTION}

$\mathrm{T}$ O TRANSMIT data along the channel, the digital information is converted into electrical impulses or waveforms. This process is called channel coding. Channel coding aims to bring a digital signal into conformity with the physical characteristics of the transmission channel and to ensure synchronization in the receiver [1]. The other purpose of the channel coding process is to reduce the effect of some disturbing elements that the data has encountered in the transmission phase as much as possible. The process ensures that the data is delivered to the receiver with minimum error.

S. KARAGOL is with Department of Electrical and Electronics Engineering, Ondokuz Mayis University, Samsun, Turkey, (e-mail: serap.karagol@omu.edu.tr) (D

D. YILDIZ, is with Department of Electrical and Electronics Engineering, Ondokuz Mayis University, Samsun, Turkey, (e-mail: dogan.yildiz@omu.edu.tr)

Manuscript received September 13, 2017; accepted January 08, 2018. DOI: $10.17694 /$ bajece.410238
The Reed-Solomon (RS) coding is one of the error correction methods that can be used to obtain the message properly. This form of transmission is commonly known as the Forward Error Correction (FEC) [2]. An error correction code comprises of algorithms and techniques that include two basic operations which are encoding and decoding [3]. Recently, several studies have been carried out using different channel coding methods in order to realize data transmission with minimum loss. Miah and Rahman [4] used a wireless communication simulator that included Gray coding, modulation, different channel models (frequency selective fading channels, smooth fading channels, Additive White Gaussian Noise (AWGN)), channel estimation, adaptive equalization and demodulation. Subsequently, they tested the effects of different channel models on transmitted data using Quadrature Phase Shift Keying (QPSK) schemes at the receiver. In [5], a system for data transmitting over a mobile audio channel based on the M-Phase Shift Keying (M-PSK) modulation with optimized parameters was proposed. Rashed et al. [6] investigated the effects of Cyclic Residual Codes and convolutional codes on the transmission performance of audio signals from AWGN and Rayleigh, Rician faded channels. In [7], measuring voice quality in VOIP communication was aimed. More specifically, besides the channel coding and compression methods, the effect of wireless channel conditions on the quality of the voice signal received was investigated.

In the study of [8], audio signal that is $5 \mathrm{sec}$ and in .wav format where each sample was expressed with 8 bits that has 8 $\mathrm{kHz}$ sampling frequency was recorded in the MATLAB environment. This obtained audio signal was coded with the Cyclic Coding Method by applying to the AWGN noisy channel. Binary Phase Shift Keying (BPSK) is used for the modulation of the audio signal. Finally, the difference between the original signal and the received signal was observed by drawing the Bit Error Rate (BER) performance curve. In [9], Bhatti used Reed-Solomon coding and Code Division Multiple Access (CDMA) methods unlike in [8].

Wavelet transforms have also been used in some topics on channel coding. In the study [10], a wavelet-based voice-coded communication system was applied to compress the size of the audio signal and the performance evaluation of this algorithm was performed. In [11], some applications of Discrete Wavelet Transform (DWT) have been described for the problem of extracting information from non-speech sounds. 
In the first part of this study, two audio signals were recorded for $5 \mathrm{sec}$, in .wav format where each samples were expressed with 8 bits that has $8 \mathrm{kHz}$ sampling frequency in MATLAB environment. These obtained audio signals were coded with the Reed-Solomon Coding Method by applying to the AWGN noisy channel. Binary Phase Shift Keying (BPSK) was used for the modulation of the audio signals. After modulating with BPSK, CDMA encoded signals were spread. The signals were then dispread and demodulated after passing through the AWGN channel. Finally, the differences between the original signals and the received signals were observed by drawing the Bit Error Rate (BER) performance curve. In the second part of the study, four wavelet transform families at different levels were applied to the audio signals and the performances of these classes were compared.

\section{AUdio TRAnSMISSION STEPS}

In this study, the five second length audio signals are passed through the steps of sampling, quantization and A/D conversion and AWGN noisy RS coded channel.

\section{A. Channel Coding}

The main aim of the channel coding process, which has an important place in communication systems, is to reduce transmission errors. Therefore, the coding made for this aim can also be called error control coding. To minimize the error in communication systems, control bits which contain no information and only provide error checking are added to the data directory. Since the added control bits do not contain information, redundancy occurs in the transmitted data. If the receiver decodes each bit independent from the others, it decides on the majority of the information bits. This is also a method for reducing the error to the minimum.

In this study, Reed-Solomon coding method is used for channel coding process.

\section{B. Reed-Solomon Codes}

Irving Reed and Gus Solomon published a paper in the Journal of the Society for Industrial and Applied Mathematics in 1960 [12]. These codes are used in many applications today due to their powerful performances. As example of these applications, compact disc players and deep space applications can be shown.

Reed-Solomon (R-S) Codes are cyclic and non-binary codes. They have symbols consisting of $\mathrm{m}$-bit arrays where $\mathrm{m}$ is an integer greater than 2. R-S (n, k) codes on m-bit symbols exist for all $k$ and $n$ for which

$$
0<k<n<2 m+2
$$

In Eq. (1), the symbol $k$ represents the number of data symbols being encoded and $n$ represents the total number of code symbols in the encoded block.

For conventional R-S $(n, k)$ code,

$$
(n, k)=(2 m-1,2 m-1-2 t)
$$

where $t$ is the symbol-error correcting capability of the code and $n-k=2 t$ is the number of parity symbols.

The distance between two code words in non-binary codes is defined as the number of different bits in the sequences. For Reed-Solomon codes, the code minimum distance is given by

$$
d_{\text {min }}=n-k+1
$$

The code can correct $t$ bits or fewer errors than $t$ bits and any combination of these errors, where $t$ can be stated as

$$
t=\left\lfloor\frac{d_{\min }-1}{2}\right\rfloor=\left\lfloor\frac{n-k}{2}\right\rfloor
$$

and $\lfloor x\rfloor$ represents the largest integer less than $\mathrm{x}$. Eq. (4) for R$\mathrm{S}$ codes shows that up to $2 \mathrm{t}$ bit parity symbols are needed to correct the $\mathrm{t}$ bit symbol error. The decoder has $\mathrm{n}-\mathrm{k}$ redundant symbols for error correction. A redundant symbol is used to locate each error. Another redundant symbol is used to find the correct value of the faulty value.

In implementation of $(255,251)$ code, it is desired to correct up to 3 symbol errors i.e. $t=2$ and $m=8$ which is the number of data bits per symbol. Numerically, it can be expressed as from Eq. (5).

$$
(n, k)=\left(2^{m}-1,2^{m}-1-2 t\right)
$$

RS Codes focus on the evaluation of polynomials over the elements in a finite field called as Galois Field (GF) [9]. The primitive polynomial for $m=8$ is given by

$$
f(x)=x^{8}+x^{4}+x^{3}+x^{2}+1
$$

The RS code $(255,251)$ is used in this research study.

\section{Pseudo Noise (PN) Sequences and CDMA Implementation}

A Pseudo-random Noise (PN) sequence which only includes binary numbers is used in this paper. The receiver should be able to reject other interfering the Spread Spectrum (SS) signals and/or prevent false correlation with CDMA systems [9]. In CDMA implementation, there are only two users i.e. $\mathrm{N}=2$ for this study. The BPSK modulated code functions are used for $(255,251)$ code as

$$
\begin{aligned}
& \text { Pseudo noise } 1=\left[\begin{array}{llllllllllllll}
0 & 0 & 0 & 1 & 0 & 0 & 1 & 1 & 0 & 1 & 0 & 1 & 1 & 1
\end{array}\right] \text {; }
\end{aligned}
$$

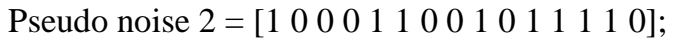

Two audio signals in the form of .wav file are recorded since there are two different data requirements for CDMA application.

\section{WAVELET TRANSFORM}

Wavelets are a method that can be applied to many different fields including applied mathematics, signal processing techniques, audio and image compression techniques. The 
wavelets were first used by Jean Morlet and A. Grossman for geographic information systems. In fact, the basic beginning of the wavelets extends to Joseph Fourier and to his Fourier transformation. With the emergence of Fourier equations after 1807, mathematicians tented to frequency analyzes for signal recognition. In 1977, Esteban and Galand introduced a new filter concept, but in this way the error was high in regaining the main signal [13]. The wavelet term was first used in 1984 by Morlet and Grossman in quantum physics studies [14]. In 1987 Mallat emerged the relation between wavelet and filter groups. Meyer revealed the first wave named his name [15]. This was a function that could be used in continuous applications, as opposed to Haar wavelets. Over the years, Ingrid Daubhecies has become the basis for many of today's application by coming up with set of vertical base wavelet series [16]. Wavelet functions are derived from the main wavelet by varying various parameters.

\section{Simulation Results}

The five second length audio signals were recorded in MATLAB environment with $\mathrm{fs}=8 \mathrm{kHz}$ sampling frequency and 8 bits resolution. The first and second audio signals are shown in Fig. 1 and Fig. 2 respectively. In the second step, amplitude values between -1 and 1 are mapped to the range of 0 to 255 and these values are expressed by the 8 bit binary number system. The signals obtained in the second step are transformed into Galois space and the $G$ generator matrix is formed appropriately. RS channel coding is performed with these components. AWGN is added and the noisy signals are modulated with BPSK in the fourth step. After modulation process through, both audio signals are spreaded by using CDMA. Then, both signals are dispreaded and demodulated

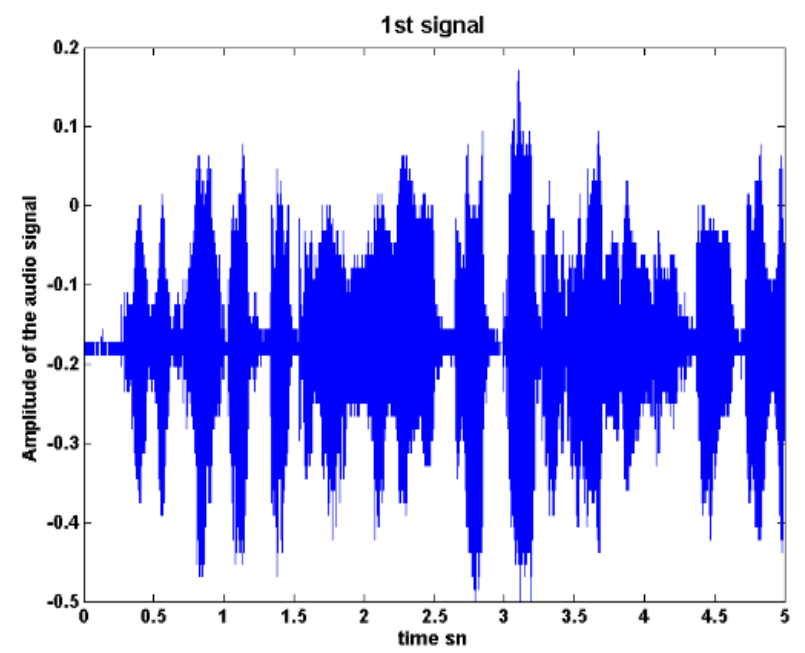

Fig. 1. $1^{\text {st }}$ original signal

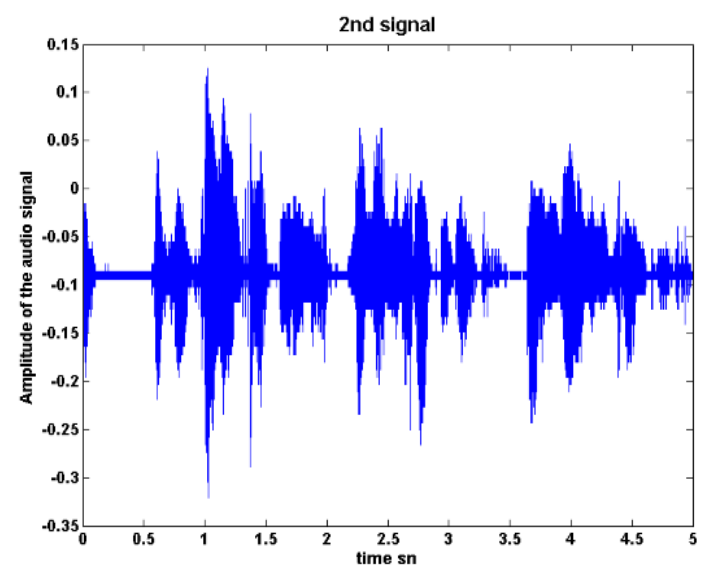

Fig. 2. $2^{\text {nd }}$ original signal

In the second part of the study, four wavelet transform families at different levels were applied to the audio signals and the performances of these classes were compared. Using wavelet transform, instead of the original data, compressed data at different levels is inserted into the designed communication system and obtained signals at the output are observed. For example, the number of samples after compression with first order wavelet transform became 20000 (40000 samples before compression) samples. According to Table I and Table II, the Mean Square Error (MSE) performances of Daubechies wavelet family $\mathrm{db} 1$ are the best at level 4 for both signals.

TABLE I.

MSE PERFORMANCES OF WAVELET TRANSFORM FAMILIES FOR SIGNAL 1

\begin{tabular}{|c|c|c|c|c|c|}
\hline \multirow{2}{*}{ Wavelet classes } & \multicolumn{5}{|c|}{ MSE values } \\
\cline { 2 - 6 } & 1. order & 2. order & 3. order & 4. order \\
\hline \multirow{4}{*}{ Daubec. } & $\mathrm{db} 1$ & $1.03 \mathrm{E}-05$ & $2.83 \mathrm{E}-06$ & $1.56 \mathrm{E}-06$ & $\mathbf{4 . 4 0 E - 0 7}$ \\
\cline { 2 - 6 } & $\mathrm{db} 2$ & $4.77 \mathrm{E}-05$ & $1.46 \mathrm{E}-04$ & $6.49 \mathrm{E}-05$ & $7.35 \mathrm{E}-06$ \\
\cline { 2 - 6 } & $\mathrm{db} 3$ & $1.17 \mathrm{E}-04$ & $1.04 \mathrm{E}-04$ & - & - \\
\hline \multirow{4}{*}{ Symlet } & sym1 & $9.31 \mathrm{E}-06$ & $4.82 \mathrm{E}-06$ & $2.26 \mathrm{E}-06$ & $8.39 \mathrm{E}-07$ \\
\cline { 2 - 6 } & sym2 & $4.89 \mathrm{E}-05$ & $1.33 \mathrm{E}-04$ & $6.10 \mathrm{E}-05$ & $7.62 \mathrm{E}-06$ \\
\cline { 2 - 6 } & sym3 & $1.22 \mathrm{E}-04$ & $1.03 \mathrm{E}-04$ & - & - \\
\hline \multirow{4}{*}{ Coiflet } & coif1 & $1.18 \mathrm{E}-04$ & $9.95 \mathrm{E}-05$ & - & - \\
\cline { 2 - 6 } & coif2 & $2.02 \mathrm{E}-04$ & $9.68 \mathrm{E}-05$ & $3.24 \mathrm{E}-05$ & - \\
\cline { 2 - 6 } & coif3 & $1.51 \mathrm{E}-04$ & $1.01 \mathrm{E}-04$ & - & - \\
\hline \multirow{4}{*}{ Biorth. } & bior1.1 & $1.29 \mathrm{E}-05$ & $4.59 \mathrm{E}-06$ & $8.27 \mathrm{E}-07$ & $4.86 \mathrm{E}-07$ \\
\cline { 2 - 6 } & bior1.3 & $1.23 \mathrm{E}-04$ & $1.17 \mathrm{E}-04$ & $5.26 \mathrm{E}-05$ & - \\
\cline { 2 - 6 } & bior1.5 & $2.45 \mathrm{E}-04$ & $1.34 \mathrm{E}-04$ & - & - \\
\hline & & & & & \\
\hline
\end{tabular}


TABLE II.

MSE PERFORMANCES OF WAVELET TRANSFORM FAMILIES FOR SIGNAL 2

\begin{tabular}{|c|c|c|c|c|c|}
\hline \multirow{2}{*}{\multicolumn{2}{|c|}{ Wavelet classes }} & \multicolumn{4}{|c|}{ MSE values } \\
\hline & & \multirow{2}{*}{$\begin{array}{l}\text { 1. order } \\
7.39 \mathrm{E}-06\end{array}$} & \multirow{2}{*}{$\begin{array}{l}\text { 2. order } \\
1.66 \mathrm{E}-06\end{array}$} & \multirow{2}{*}{$\begin{array}{l}\text { 3. order } \\
2.91 \mathrm{E}-07\end{array}$} & \multirow{2}{*}{$\begin{array}{l}\text { 4. order } \\
\text { 9.64E-08 }\end{array}$} \\
\hline \multirow{3}{*}{ Daub. } & $\mathrm{db} 1$ & & & & \\
\hline & $\mathrm{db} 2$ & $1.15 \mathrm{E}-05$ & $8.78 \mathrm{E}-06$ & $3.21 \mathrm{E}-06$ & $6.04 \mathrm{E}-07$ \\
\hline & $\mathrm{db} 3$ & $1.57 \mathrm{E}-05$ & $7.50 \mathrm{E}-06$ & - & - \\
\hline \multirow{3}{*}{ Symlet } & sym1 & 7.02E-06 & $2.21 \mathrm{E}-06$ & $6.03 \mathrm{E}-07$ & $2.92 \mathrm{E}-07$ \\
\hline & sym2 & $1.15 \mathrm{E}-05$ & $7.79 \mathrm{E}-06$ & $2.68 \mathrm{E}-06$ & $6.83 \mathrm{E}-07$ \\
\hline & sym3 & $1.48 \mathrm{E}-05$ & $6.90 \mathrm{E}-06$ & - & - \\
\hline \multirow{3}{*}{ Coiflet } & coif1 & $1.47 \mathrm{E}-05$ & $7.65 \mathrm{E}-06$ & - & - \\
\hline & coif2 & $1.81 \mathrm{E}-05$ & $5.35 \mathrm{E}-06$ & $1.66 \mathrm{E}-06$ & - \\
\hline & coif3 & $1.68 \mathrm{E}-05$ & $7.42 \mathrm{E}-06$ & - & - \\
\hline \multirow{3}{*}{ Bior. } & bior1.1 & 7.67E-06 & $2.09 \mathrm{E}-06$ & $8.54 \mathrm{E}-07$ & $1.68 \mathrm{E}-07$ \\
\hline & bior1.3 & $1.60 \mathrm{E}-05$ & $6.65 \mathrm{E}-06$ & $2.67 \mathrm{E}-06$ & - \\
\hline & bior1.5 & $1.92 \mathrm{E}-05$ & $8.11 \mathrm{E}-06$ & - & - \\
\hline
\end{tabular}

The differences between the received signals and original signals are examined by using BER vs EbNo plot as shown in Fig. 3. The bit error rate varies inversely with the signal noise value.

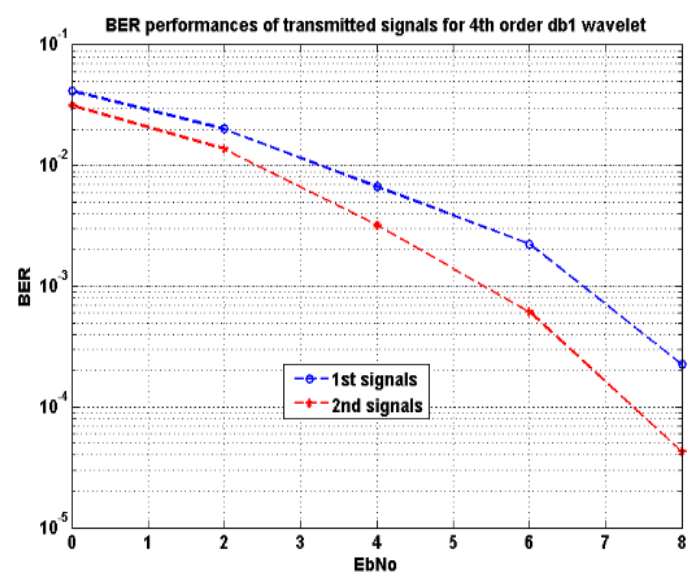

Fig. 3. BER performances of transmitted signals for 4 th order $\mathrm{db} 1$ wavelet

\section{CONCLUSION}

According to the obtained results, RS coding method is a suitable method which can be used for channel coding. The BER performance curve is obtained inversely proportional to the signal-to-noise ratio. The coding of the channel by the RS coding method has reduced the error effect of the AWGN in the transmitted operation. In the second part of this study, four wavelet transform families at different levels were applied to the audio signals and the performances of these families were compared. MSE performances were obtained at db1 of the Daubechies wavelet family at the 4th best level for both signals. After the first audio signal is transmitted from the AWGN channel, there is no difference between the transmitted and received audio signal except for some acoustic differences. With RS coding, the sampling frequency can be increased and each sample can be expressed with more bits in order to achieve better performance. However, these increases will lead to a longer transmission of the audio signal from the channel.

\section{REFERENCES}

[1] John G. Proakis and Masoud Salehi, Digital Communications, McGrawHill Inc., Fifth Edition, p.751, 2008.

[2] Lin and Daniel J Costello, Error Control Coding: Fundamentals and Applications, Englewood Cliffs, Prentice Hall, NJ, p.2, 1983.

[3] Moreira JC and Farrell PG, Essentials of Error-Control Coding, John Wiley \& Sons, England, 2006.

[4] Md. Sipon Miah, M. Mahbubur Rahman, T. K Godder, Bikash Chandra Singh and M. Tania Parvin,"Performance comparison of AWGN, flat fading and frequency selective fading channel for wireless communication system using 4QPSK", International journal of computer and information technology (IJCIT), Vol. 01, Issue 02, pp. 82-90, 2011.

[5] Béchir Taleb Ali, Geneviève Baudoin, Olivier Venard, "Data Transmission Over Mobile Voice Channel Based on M-FSK Modulation", Wireless Communications and Networking Conference (WCNC) Proc., 2013.

[6] Md. Golam Rashed, M. Hasnat Kabir, Md. Selim Reza, Md. Matiqul Islam, Rifat Ara Shams, Saleh Masum, Sheikh Enayet Ullah, "Transmission of voice signal: BER performance analysis of different FEC schemes based OFDM system over various channel", International journal of advanced science and technology, vol. 34, pp.89-100, 2011.

[7] Tiantioukas Nikolaos, "Effects of the Wireless Channel, Signal Compression and Network Architecture on Speech Quality in VOIP Networks", Master of Science in Electrical Engineering Thesis, Naval Postgraduate School Monterey, June 2007.

[8] Ali Tariq Bhatti, "Cyclic channel coding algorithm for original and received voice signal at $8 \mathrm{khz}$ using ber performance through additive white gaussian noise channel", International journal of innovative science, engineering \& technology (IJISET), Vol. 2 Issue 4, pp. 843-852, 2015.

[9] Ali Tariq Bhatti, Dr. Jung H. Kim, "implementation of reed-solomon (rs) and cdma for signaling a voice through AWGN at $8 \mathrm{KHz}$ sampling frequency using BPSK", International journal of advent research in computer and electronics (IJARCE), vol.2, no.8, pp.13-27, August 2015.

[10] Thuraya Mahmood Qaradaghi, Fatima Kamil Faek, Diana Hayder Hussein, "Investigating the Effect of Error Correcting Codes on the Compressed Speech Signals", 1st International Conference on Engineering and Innovative Technology, SU-ICEIT 2016, Salahaddin University-Erbil, Iraq, April 12-14, 2016.

[11] G. Tzanetakis, G. Essl, P. Cook, "Audio Analysis Using the Discrete Wavelet Transform", Proc. Conf. Acoustics and Music Theory Applications, September 2001.

[12] Bernard Sklar, "Digital Communications Fundamentals and Applications Second Edition", Prentice Hall P T R Upper Saddle River, New Jersey 07458.

[13] Croisier, A., Esteban, D., and Galand, C., "Perfect Channel Splitting by Use of Interpolation/Decimation/TreeDecomposition Techniques",In Proc. Int. Conf. On Info. Sciences and Systems, Greece, p. 443-446, 1976.

[14] P. M. A. K. Louis and A. Rieder, Wavelets Theory and Applications. John Wiley \& Sons, 1997

[15] S. G. Mallat, "A theory for multiresolution signal decomposition: the wavelet representation,” vol. 11, pp. 674-693, July 1989. 
[16] I. Daubechies, Ten lectures on wavelets, vol. 61 of CBMS-NSF Regional conference series in applied mathematics, Philadelphia, PA: Society for industrial and applied mathematics (SIAM), 1992.

\section{BIOGRAPHIES}

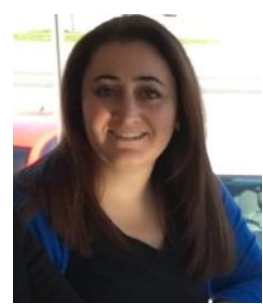

SERAP KARAGOL received the B.E. degree in Computer Engineering from the Karadeniz Technical University, Trabzon, Turkey, in 2002, and the M.S. and $\mathrm{Ph} . \mathrm{D}$. degrees in electrical engineering from North Carolina A\&T State University, Greensboro, NC USA, in 2006 and 2011, respectively. She is currently an Assistant Professor in the Department of Electrical and Electronics Engineering, Ondokuz Mayis University, Samsun Turkey. She is engaged in teaching and conducting research in circuits and systems, signal processing, modeling, system identification and wireless sensors networks. She is the advisor for more than 10 M.S. and 3 Ph. D. students.

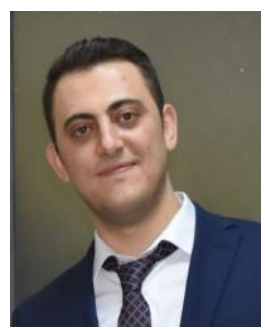

DOGAN YILDIZ born in Istanbul in 1989. He received the B.S. degree in Electrical-Electronics engineering and Mathematics from Fatih University, Istanbul, in 2013 and the M.S. degree in electricalelectronics engineering from Ondokuz Mayis University, Samsun, in 2016.

Since 2013, he has been working as research assistant with the Electrical-Electronics Engineering Department in Ondokuz Mayis University. His research interests include wireless sensor networks, localization, signal processing, telecommunication and applications, electromagnetic waves and electromagnetic radiation measurements. 